Article

\title{
Residence in Proximity of a Coal-oil-fired Thermal Power Plant and Risk of Lung and Bladder Cancer in North-eastern Italy. A Population-based Study, 1995-2009
}

\author{
Paolo Collarile1, ${ }^{*}$, Ettore Bidoli' ${ }^{1}$, Fabio Barbone ${ }^{2,3}$, Loris Zanier ${ }^{4}$, Stefania Del Zotto ${ }^{1}$, Simonetta \\ Fuser ${ }^{5}$, Fulvio Stel ${ }^{5}$, Chiara Panato ${ }^{1}$, Irene Gallai ${ }^{5}$ and Diego Serraino ${ }^{1,6}$ \\ 1 SOC Epidemiologia Oncologica, IRCCS Centro di Riferimento Oncologico di Aviano. 33081 Aviano (PN) \\ Italy; E-Mails: bidolie@cro.it (E.B.); stefania.delzotto@regione.fvg.it (S.D.Z.); chiara.panato@cro.it (C.P.); \\ serrainod@cro.it (D.S.) \\ 2 Ospedale Infantile IRCCS Burlo Garofolo di Trieste; E-Mail: fabio.barbone@burlo.trieste.it \\ 3 Dipartimento di Area Medica, Università degli studi di Udine, 33100 Udine, Italy \\ 4 Direzione Centrale Salute. Friuli Venezia Giulia, Servizio Regionale di Epidemiologia, 33100 Udine, Italy; \\ E-Mail: loris.zanier@regione.fvg.it (L.Z.) \\ 5 Agenzia Regionale per la Protezione dell'Ambientale del Friuli Venezia Giulia, 33057 Palmanova (UD), \\ Italy; E-Mails: simonetta.fuser@arpa.fvg.it (S.F.); fulvio.stel@arpa.fvg.it (F.S.); irene.gallai@arpa.fvg.it (I.G.) \\ 6 Registro Tumori del Friuli Venezia Giulia. 33081 Aviano (PN), Italy \\ * Author to whom correspondence should be addressed: E-Mail: epidemiology@cro.it; \\ Tel.: +39-434-659-354; Fax: +39-434-659-231.
}

\begin{abstract}
This study investigated the risk of lung and bladder cancers in people residing in proximity of a coal-oil-fired thermal power plant in an area of north-eastern Italy, covered by a population-based cancer registry. Incidence rate ratios (IRR) by sex, age, and histology were computed according to tertiles of residential exposure to benzene, nitrogen dioxide $\left(\mathrm{NO}_{2}\right)$, particular matter, and sulfur dioxide $\left(\mathrm{SO}_{2}\right)$ among 1076 incident cases of lung and 650 cases of bladder cancers. In men of all ages and in women under 75 years of age, no significant associations were observed. Conversely, in women aged $\geq 75$ years significantly increased risks of lung and bladder cancers were related to high exposure to benzene (IRR for highest vs. lowest tertile: 2.00 for lung cancer and 1.94 for bladder cancer) and $\mathrm{NO}_{2}$ (IRR: 1.72 for lung cancer; and 1.94 for bladder cancer). In these women, a 1.71-fold higher risk of lung cancer was also related to a high exposure to $\mathrm{SO}_{2}$. The findings of this descriptive study indicated that air pollution may have a role with regard to the risk of lung and bladder cancers, limited to women aged $\geq 75$ years. Such increased risk warrants further analytical investigations.
\end{abstract}

Keywords: air pollution; coal-fired thermal power plant; oil thermal power plant; geocoded; lung cancer; bladder cancer; North-eastern Italy

\section{Introduction}

Agents classified as IARC Group 1 lung carcinogens include personal habits and occupational and environmental exposures. Although in many populations cigarette smoking is the main cause of lung cancer, other recognized risk factors may have a relevant impact under local circumstances. Such factors include exposure to identified physical and chemical agents and their mixtures and occupational and environmental activities. The latter may entail exposures occurred in or in proximity of some industrial facilities, air pollution due to road traffic and home heating $[1,2,3,4,5,6]$. Sufficient or convincing evidence about causes of bladder cancer is associated with cigarette smoking, radiation, exposure to aromatic amines, arsenic and inorganic arsenic compounds, Schistosoma haematobium, and work in occupations such as aluminum production, painting, and rubber production $[7,8,9]$. However, a positive association between bladder cancer and outdoor air pollution has recently emerged [10]. With specific reference to the carcinogenic effect of combustion of coal, burning coal inside the home for the purpose of heating or cooking produces particulate and gas emissions that are lung carcinogens (IARC Group I). Additional substances derived from coal, also recognized as carcinogens, are: coal-tar pitch, soot, diesel engine exhaust, 
and related occupations (i.e., coal gasification, coke production, iron and steel founding). However, the extension and impact of the carcinogenic effects of emissions from coal and coal-oil-fired plants is a matter of debate, especially when such effects are compared with other local sources of air pollution and with alternative modes of energy production.

\section{Materials and Methods}

The city of Monfalcone is located in the Friuli Venezia Giulia region, northeastern Italy, and shares with 13 surrounding municipalities a concentration of industries (a power plant, a large shipyard, a paper mill, and other manufacturing industries) and several transport infrastructure such as port, airport, and highway.

The coal-fired and oil thermal power plant is located near the city center of Monfalcone since 1965; over time, the power plant has undergone several additions and changes. Until 1969, there was only one coal-fired power generator with a 60-meter high smokestack. In 1970, another coal-fired power generator was added along with another 90-meter high smokestack. In 1984, two oil power generators were added and the smokestacks were replaced by one single 154-meter high smokestack. In 1990, to reduce the suspension of coal dust, the coal conveyor belt was depressurized.

Throughout the years, the residents of the 14 municipalities have set up citizens committees for environmental controls over the emissions of the thermal power plant, and have solicited epidemiological monitoring of the potential adverse health effects associated with air pollution. In 2014, to respond to these public concerns, the Friuli Venezia Giulia Region implemented the «Health \& Environment Regional Observatory». Point and diffuse emissions, within the 14 municipalities, are measured by the Regional Environmental Protection Agency (ARPA-FVG). The coal-fired and oil thermal power plant, other industries, port, airport, home heating, and highway in the study area contribute pro rata to the overall atmospheric concentrations of fine particulate matter (PM10), benzene $\left(\mathrm{C}_{6} \mathrm{H}_{6}\right)$, nitrogen dioxide $\left(\mathrm{NO}_{2}\right)$, and sulfur dioxide $\left(\mathrm{SO}_{2}\right)$. The study area was defined according to a deposition model of the specific emissions of $\mathrm{NO}_{2}$ of the coal-fired thermal power plant.

Since 1995, the incidence of cancer in the whole population of the Friuli Venezia Giulia region (1,200,000 inhabitants) is being recorded by the population-based cancer registry (CR-FVG) (http://ci5.iarc.fr/).

In this study we obtained the structure of the residential population (by sex, age in quinquennia, and calendar year) using the same methodology applied in our previous investigation [11]. In the study area, $96.3 \%$ of residential addresses, extracted from regional healthcare population database between 1995 and 2009, were geocoded. The computerized structure of CR-FVG and regional healthcare population database allows a full integration of the two databases. We extracted from the population-based CR-FVG all incident cases of lung (i.e., 817 men and 285 women) and bladder cancers (i.e., 505 men and 157 women) diagnosed during 1995-2009 among the population residing in the 14 municipalities Twenty-six cases of lung cancer (16 men and 10 women) and 12 cases of bladder cancers ( 8 men and 4 women) were excluded from the study, due to missing valid addresses recorded in the regional healthcare population database. We disentangled incidence data by age (in quinquennia), sex, calendar year of diagnosis, and histological subtype (for lung carcinoma). We used the International Classification of Diseases, 10th edition, to identify lung cancer (C33, C34) and bladder cancer (C67, D09.0, D41.4). We used the International Classification of Disease for Oncology (ICDO-3) for the classification of histologic subtypes of lung cancer: adenocarcinoma (ADK) squamous cell carcinoma (SCC), and other and unspecified morphologies (OLC). Age-standardized incidence rates (ASRs) were computed.

The residential exposure was defined a priori by ARPA-FVG that recovers the point emission data of $\mathrm{C}_{6} \mathrm{H}_{6}, \mathrm{NO}_{2}, \mathrm{PM} 10, \mathrm{SO}_{2}$ reported by individual industries and data on road traffic, port, airport, home heating, and local environmental monitoring system. Then, the residential exposure to air pollution was modelized for the overall area on a 400x400 meter grid. Geocoded lung and 
bladder cancer cases and the population were linked to this grid using Geomedia software, a geographic information system (GIS) (version desktop 2015; Hexagon Geospatial - Stockholm Sweden). Cases and population were thus exported to compute indicators by an ad-hoc software. An exploratory high exposure (i.e., the highest tertile versus the lowest tertile) analysis was conducted to assess the risk of lung and bladder cancers according to residential exposure to the above mentioned four pollutants. Data on pollutants refer to 1998, a year that ARPA-FVG considers as a good proxy of exposure in past years, taking into account the vehicle fleet, emissions from the power plant, and other industries, and the type of home heating.

Yearly age-standardized (to the 2001 European population) incidence rates (ASRs-EU) per 100,000 inhabitants were calculated for the whole examined period in both sexes and in two age groups ( $<75$ and $\geq 75$ years), according to tertiles of exposure. ASRs and their corresponding 95\% confidence intervals (CI) were calculated using SAS Enterprise Guide (version 7.1: SAS Institute North Carolina USA). Incidence Rate Ratios (IRRs) and 95\% confidence intervals (CI) [12] were computed from the ASRs, considering the lowest tertile of exposure to different pollutants as the reference category.

We calculated annual percent change (APC) $[13,14]$ of incidence rates using Joinpoint software, for the whole 1995-2009 period in both sexes and by the two age groups ( $<75$ and $\geq 75$ years) according to tertile of exposures. Statistical significance $(p<0.05)$ of annual APC was calculated using a Student's t-distribution [14]. To calculate APC, we applied the same assumptions used in our previous study [11].

\section{Results}

Table 1 reports the number of overall incident lung and bladder cancer cases, the ASRs with corresponding 95\% CI, according to age and sex. Different incidence rates were observed in lung cancer by histological types in women of all ages with ASR of adenocarcinoma greater than squamous cell ones, and in men aged 75 years or older (i.e., the squamous cell carcinoma -SCC- type was more frequent than the adenocarcinoma -ADK-type).

Table 1. Number of incident cases of lung and bladder carcinomas, age-standardized incidence rates (ASR) with corresponding 95\% confidence intervals (CI), by sex and age group. 1995-2009 in 14 municipalities

\begin{tabular}{|c|c|c|c|c|c|c|c|c|c|c|c|c|c|c|c|c|c|c|}
\hline & \multicolumn{6}{|c|}{$<75$ Years } & \multicolumn{6}{|c|}{$>=75$ Years } & \multicolumn{6}{|c|}{ All ages } \\
\hline & \multicolumn{3}{|c|}{ Men } & \multicolumn{3}{|c|}{ Women } & \multicolumn{3}{|c|}{ Men } & \multicolumn{3}{|c|}{ Women } & \multicolumn{3}{|c|}{ Men } & \multicolumn{3}{|c|}{ Women } \\
\hline & $\mathrm{N}$ & ASR & $95 \% \mathrm{CI}$ & $\mathrm{N}$ & ASR & $95 \% \mathrm{CI}$ & $\mathrm{N}$ & ASR & $95 \%$ CI & $\mathrm{N}$ & ASR & $95 \% \mathrm{CI}$ & $\mathrm{N}$ & ASR & $95 \% \mathrm{CI}$ & $\mathrm{N}$ & ASR & $95 \% \mathrm{CI}$ \\
\hline All cancer* & 3813 & 442.2 & $(427.9-456.6)$ & 2716 & 314.9 & $(302.5-327.4)$ & 1892 & 3383 & (3228.8-3537.3) & 1599 & 1593.4 & (1512.4-1674.4) & 5705 & 559.9 & $(544.8-575)$ & 4315 & 366.1 & (353.7-378.5) \\
\hline Bladder cancer & 304 & 34.3 & $(30.4-38.2)$ & 79 & 8.6 & $(6.7-10.6)$ & 193 & 339.5 & $(291-388)$ & 74 & 74.2 & $(56.6-91.8)$ & 497 & 46.5 & $(42.3-50.8)$ & 153 & 11.4 & $(9.2-13.3)$ \\
\hline Lung cancer & & & & & & & & & & & & & & & & & & \\
\hline All lung carcinoma & 527 & 58.4 & $(53.4-63.5)$ & 153 & 16 & $(13.4-18.7)$ & 274 & 496.5 & $(437-555.9)$ & 122 & 126 & $(102.8-149.1)$ & 801 & 75.9 & $(70.5-81.3)$ & 275 & 20.4 & $(17.7-23.1)$ \\
\hline Adenocarcinoma & 131 & 14.6 & $(12.1-17.2)$ & 58 & 6.5 & $(4.8-8.2)$ & 55 & 100.7 & $(73.8-127.6)$ & 24 & 26.8 & $(15.7-37.8)$ & 186 & 18.1 & $(15.4-20.8)$ & 82 & 7.3 & $(5.6-9)$ \\
\hline Squamous cell & 135 & 14.7 & $(12.2-17.2)$ & 23 & 2.3 & $(1.3-3.3)$ & 69 & 129.8 & $(98.9-160.7)$ & 17 & 19.9 & $(10.2-29.6)$ & 204 & 19.3 & $(16.6-22)$ & 40 & 3 & $(2-4)$ \\
\hline Other & 261 & 29 & $(25.5-32.6)$ & 72 & 7.2 & $(5.5-8.9)$ & 150 & 266 & (222.9-309.1) & 81 & 79.3 & $(61.4-97.2)$ & 411 & 38.5 & $(34.7-42.4)$ & 153 & 10.1 & $(8.3-11.9)$ \\
\hline
\end{tabular}

Note: ASR calculated from age-standardized rates on 2001 EU population; ${ }^{*}$ ): All cancers (non melanoma excluded).

Table 2 reports the number of lung cancers, the IRRs with corresponding $95 \% \mathrm{CI}$, according to age, sex, and tertile of exposure to $\mathrm{C}_{6} \mathrm{H}_{6}, \mathrm{NO}_{2}, \mathrm{PM} 10$, and $\mathrm{SO}_{2}$. No excess risks emerged in both sexes under 75 years of age. An increasing gradient in ASR of lung cancer, according to tertiles of exposure to $\mathrm{C}_{6} \mathrm{H}_{6}, \mathrm{NO}_{2}$, and $\mathrm{SO}_{2}$, emerged only in women aged 75 years or older (Table S1). Only in women aged 75 years or older, the risk of lung cancer increased with increasing degree of residential exposure to $\mathrm{C}_{6} \mathrm{H}_{6}$ (IRR=1.86, 95\%CI: 1.15-3.00 for intermediate tertile vs lowest tertile; IRR=2.00, 95\%CI: 1.23-3.25 for highest tertile), $\mathrm{NO}_{2}$ (IRR=1.70, 95\%CI: 1.07-2.71 for intermediate tertile; 
IRR=1.72, 95\%CI: 1.07-2.77 for highest tertile), and $\mathrm{SO}_{2}$ (IRR=1.55, 95\%CI: 0.96-2.49 for intermediate tertile; IRR=1.71, 95\%CI: 1.07-2.73 for highest tertile). The risk of lung cancer with increasing exposure to PM10 was not linear: IRR=2.11, 95\%CI: 1.33-3.33 for intermediate tertile, and IRR=1.57, 95\%CI: 0.94-2.60 for highest tertile.

Table 2. Number of incident cases of lung cancer, incidence rate ratio (IRR) with corresponding 95\% confidence intervals (CI), by sex, tertile of exposure, and age group. 1995-2009 in 14 municipalities

\begin{tabular}{|c|c|c|c|c|c|c|c|c|c|c|c|c|c|c|c|c|c|c|}
\hline & \multicolumn{6}{|c|}{$<75$ Years } & \multicolumn{6}{|c|}{$>=75$ Years } & \multicolumn{6}{|c|}{ All ages } \\
\hline & \multicolumn{3}{|c|}{ Men } & \multicolumn{3}{|c|}{ Women } & \multicolumn{3}{|c|}{ Men } & \multicolumn{3}{|c|}{ Women } & \multicolumn{3}{|c|}{ Men } & \multicolumn{3}{|c|}{ Women } \\
\hline & $\mathrm{N}$ & IRR & $95 \% \mathrm{CI}$ & $\mathrm{N}$ & IRR & $95 \% \mathrm{CI}$ & $\mathrm{N}$ & IRR & $95 \%$ CI & $\mathrm{N}$ & IRR & $95 \% \mathrm{CI}$ & $\mathrm{N}$ & IRR & $95 \% \mathrm{CI}$ & $\mathrm{N}$ & IRR & $95 \% \mathrm{CI}$ \\
\hline \multicolumn{19}{|c|}{$\mathrm{C}_{6} \mathrm{H}_{6}(\mu \mathrm{g} / \mathrm{m} 3)$} \\
\hline$<1.1$ & 175 & 1 & & 52 & 1 & & 97 & 1 & & 25 & 1 & & 272 & 1 & & 77 & 1 & \\
\hline $1.1-1.8$ & 181 & 1.07 & $(0.87-1.32)$ & 53 & 0.94 & $(0.64-1.38)$ & 89 & 0.91 & $(0.71-1.18)$ & 51 & 1.86 & $(1.15-3.00)$ & 270 & 1.03 & $(0.87-1.22)$ & 104 & 1.09 & $(0.81-1.46)$ \\
\hline$>1.8$ & 171 & 1.04 & $(0.84-1.29)$ & 48 & 0.95 & $(0.64-1.41)$ & 88 & 0.97 & $(0.75-1.26)$ & 46 & 2.00 & $(1.23-3.25)$ & 259 & 1.02 & $(0.86-1.21)$ & 94 & 1.12 & $(0.83-1.52)$ \\
\hline \multicolumn{19}{|c|}{$\mathrm{NO}_{2}(\mu \mathrm{g} / \mathrm{m} 3)$} \\
\hline$<16.9$ & 172 & 1 & & 49 & 1 & & 95 & 1 & & 28 & 1 & & 267 & 1 & & 77 & 1 & \\
\hline $16.9-19.6$ & 184 & 1.13 & $(0.92-1.39)$ & 57 & 1.12 & $(0.77-1.65)$ & 88 & 0.93 & $(0.72-1.20)$ & 50 & 1.70 & $(1.07-2.71)$ & 272 & 1.07 & $(0.91-1.27)$ & 107 & 1.23 & $(0.92-1.65)$ \\
\hline$>19.6$ & 171 & 1.07 & $(0.86-1.32)$ & 47 & 0.99 & $(0.67-1.48)$ & 91 & 1.04 & $(0.80-1.34)$ & 44 & 1.72 & $(1.07-2.77)$ & 262 & 1.06 & $(0.89-1.25)$ & 91 & 1.14 & $(0.84-1.54)$ \\
\hline \multicolumn{19}{|c|}{$\mathrm{PM}_{10}(\mu \mathrm{g} / \mathrm{m} 3)$} \\
\hline$<40.6$ & 181 & 1 & & 58 & 1 & & 94 & 1 & & 26 & 1 & & 275 & 1 & & 84 & 1 & \\
\hline $40.6-51.9$ & 183 & 1.03 & $(0.84-1.27)$ & 51 & 0.82 & $(0.57-1.20)$ & 97 & 1.00 & $(0.78-1.28)$ & 61 & 2.11 & $(1.33-3.33)$ & 280 & 1.02 & $(0.87-1.21)$ & 112 & 1.02 & $(0.77-1.36)$ \\
\hline$>51.9$ & 163 & 0.99 & $(0.81-1.23)$ & 44 & 0.81 & $(0.55-1.20)$ & 83 & 1.01 & $(0.78-1.32)$ & 35 & 1.57 & $(0.94-2.60)$ & 246 & 1.00 & $(0.84-1.19)$ & 79 & 0.93 & $(0.68-1.27)$ \\
\hline $\mathrm{SO}_{2} \quad(\mu \mathrm{g} /$ & & & & & & & & & & & & & & & & & & \\
\hline$<34.6$ & 184 & 1 & & 52 & 1 & & 99 & 1 & & 27 & 1 & & 283 & 1 & & 79 & 1 & \\
\hline $34.6-37.5$ & 175 & 1.04 & $(0.85-1.28)$ & 47 & 0.88 & $(0.59-1.30)$ & 91 & 1.01 & $(0.79-1.30)$ & 45 & 1.55 & $(0.96-2.49)$ & 266 & 1.03 & $(0.87-1.22)$ & 92 & 0.98 & $(0.73-1.33)$ \\
\hline$>37.5$ & 168 & 0.97 & $(0.79-1.20)$ & 54 & 1.06 & $(0.72-1.55)$ & 84 & 0.87 & $(0.67-1.13)$ & 50 & 1.71 & $(1.07-2.73)$ & 252 & 0.95 & $(0.80-1.12)$ & 104 & 1.16 & $(0.87-1.56)$ \\
\hline
\end{tabular}

The analysis of the risk of lung cancer was also carried out according to histological subtypes: SCC, ADK, and other lung cancer (OLC) types. A gradient in ASR of lung cancer, according to histological type and tertile of residential exposure to all pollutants, did not emerge in both sexes and in both classes of ages (Table S2). IRRs of lung cancer by histologic subtype (Table S3) highlighted a significantly increased risk of OLC, in women aged 75 years or older, for highest tertile of exposure to $\mathrm{C}_{6} \mathrm{H}_{6}$ (IRR=2.02, 95\% CI: 1.14-3.6), $\mathrm{NO}_{2}$ (IRR=1.70, 95\% CI: 0.87-3.00), PM10 (IRR=2.00, 95\% CI: 1.11-3.62), and $\mathrm{SO}_{2}$ (IRR=2.54, 95\% CI: 1.4-4.63). No excess risk of OLC emerged in women under 75 years of age and in men of all ages. A significantly increased risk of SCC was observed in women aged 75 years or older, for the intermediate tertile of exposure to $\mathrm{C}_{6} \mathrm{H}_{6}$ (IRR=8.20, 95\% CI: 1.06-63.52), $\mathrm{NO}_{2}$ (IRR=8.26, 95\% CI: 1.07-63.99), and PM10 (IRR=4.99, 95\% CI: 1.13-22.13). This risk was not observed for the highest tertile of exposure to all of the examined pollutants, and no excess risk of SCC emerged in women under 75 years of age and in men in both classes of ages. Moreover, no significant associations with the risk of ADK emerged in both sexes and classes of ages.

Table 3 reports the number of incident cases of bladder cancer, the IRRs according to age, sex, and tertiles of exposure. An increasing gradient in ASR of bladder cancer, according to tertiles of exposure to all pollutants, emerged only in women of all ages, for example from 9.3 cases/100,000/year with lowest exposure to $\mathrm{C}_{6} \mathrm{H}_{6}$ to 13.4 cases/100,000/year with highest exposure. A similar gradient in ASR of bladder cancer emerged for other pollutants (Table S4). No excess risk emerged in both sexes under 75 years of age, and only in women aged 75 years or older the risk of bladder cancer increased according to increasing degree of exposure to $\mathrm{C}_{6} \mathrm{H}_{6}$ (IRR=2.39, 95\%CI: 1.29-4.44 for intermediate tertile; IRR=1.94, 95\% CI: 1.01-3.74 for highest tertile) and $\mathrm{NO}_{2}$ (IRR=1.97, 
95\% CI: 1.07-3.63 for intermediate tertile; IRR=1.94, 95\% CI: 1.03-3.65 for highest tertile). The risk of bladder cancer by increasing levels of residential exposure to PM10 or $\mathrm{SO}_{2}$ was not linear.

Table 3. Number of incident cases of bladder cancer incidence rate ratio (IRR) with corresponding $95 \%$ confidence intervals (CI), by sex, tertile of exposure, and age group. 1995-2009 in 14 municipalities

\begin{tabular}{|c|c|c|c|c|c|c|c|c|c|c|c|c|c|c|c|c|c|c|}
\hline & \multicolumn{6}{|c|}{$<75$ Years } & \multicolumn{6}{|c|}{$>=75$ Years } & \multicolumn{6}{|c|}{ All ages } \\
\hline & \multicolumn{3}{|c|}{ Men } & \multicolumn{3}{|c|}{ Women } & \multicolumn{3}{|c|}{ Men } & \multicolumn{3}{|c|}{ Women } & \multicolumn{3}{|c|}{ Men } & \multicolumn{3}{|c|}{ Women } \\
\hline & $\mathrm{N}$ & IRR & $95 \%$ CI & $\mathrm{N}$ & IRR & $95 \%$ CI & $\mathrm{N}$ & IRR & $95 \%$ CI & $\mathrm{N}$ & IRR & $95 \%$ CI & $\mathrm{N}$ & IRR & $95 \%$ CI & $\mathrm{N}$ & IRR & $95 \%$ CI \\
\hline \multicolumn{19}{|c|}{$\mathrm{C}_{6} \mathrm{H}_{6}(\mu \mathrm{g} / \mathrm{m} 3)$} \\
\hline$<1.1$ & 102 & 1 & & 25 & 1 & & 65 & 1 & & 14 & 1 & & 167 & 1 & & 39 & 1 & \\
\hline $1.1-1.8$ & 110 & 1.12 & $(0.86-1.47)$ & 25 & 0.89 & $(0.51-1.55)$ & 65 & 0.96 & $(0.70-1.31)$ & 35 & 2.39 & $(1.29-4.44)$ & 175 & 1.07 & $(0.87-1.33)$ & 60 & 1.16 & $(0.77-1.73)$ \\
\hline$>1.8$ & 92 & 0.95 & $(0.71-1.25)$ & 29 & 1.33 & $(0.78-2.26)$ & 63 & 1.05 & $(0.77-1.44)$ & 25 & 1.94 & $(1.01-3.74)$ & 155 & 0.98 & $(0.79-1.22)$ & 54 & 1.44 & $(0.95-2.17)$ \\
\hline \multicolumn{19}{|c|}{$\mathrm{NO}_{2}(\mu \mathrm{g} / \mathrm{m} 3)$} \\
\hline$<16.9$ & 100 & 1 & & 25 & 1 & & 66 & 1 & & 15 & 1 & & 166 & 1 & & 40 & 1 & \\
\hline $16.9-19.6$ & 108 & 1.13 & $(0.86-1.49)$ & 22 & 0.79 & $(0.44-1.40)$ & 61 & 0.92 & $(0.67-1.27)$ & 32 & 1.97 & $(1.07-3.63)$ & 169 & 1.07 & $(0.86-1.33)$ & 54 & 1.02 & $(0.68-1.54)$ \\
\hline$>19.6$ & 96 & 1.02 & $(0.77-1.35)$ & 32 & 1.44 & $(0.85-2.43)$ & 66 & 1.10 & $(0.80-1.49)$ & 27 & 1.94 & $(1.03-3.65)$ & 162 & 1.04 & $(0.84-1.30)$ & 59 & 1.53 & $(1.03-2.29)$ \\
\hline \multicolumn{19}{|c|}{$\mathrm{PM}_{10}(\mu \mathrm{g} / \mathrm{m} 3)$} \\
\hline$<40.6$ & 96 & 1 & & 27 & 1 & & 72 & 1 & & 15 & 1 & & 168 & 1 & & 42 & 1 & \\
\hline $40.6-51.9$ & 114 & 1.18 & $(0.90-1.55)$ & 27 & 0.91 & $(0.53-1.55)$ & 69 & 0.92 & $(0.68-1.26)$ & 37 & 2.39 & $(1.31-4.35)$ & 183 & 1.10 & $(0.89-1.36)$ & 64 & 1.16 & $(0.78-1.71)$ \\
\hline$>51.9$ & 94 & 1.06 & $(0.80-1.41)$ & 25 & 1.10 & $(0.64-1.90)$ & 52 & 0.88 & $(0.63-1.23)$ & 22 & 1.78 & $(0.92-3.44)$ & 146 & 1.00 & $(0.80-1.25)$ & 47 & 1.21 & $(0.80-1.84)$ \\
\hline \multicolumn{19}{|c|}{$\mathrm{SO}_{2} \quad(\mu \mathrm{g} / \mathrm{m} 3)$} \\
\hline$<34.6$ & 98 & 1 & & 24 & 1 & & 68 & 1 & & 18 & 1 & & 166 & 1 & & 42 & 1 & \\
\hline $34.6-37.5$ & 115 & 1.28 & $(0.98-1.68)$ & 24 & 1.03 & $(0.58-1.81)$ & 54 & 0.89 & $(0.64-1.24)$ & 32 & 1.75 & $(0.98-3.12)$ & 169 & 1.16 & $(0.94-1.44)$ & 56 & 1.19 & $(0.80-1.78)$ \\
\hline$>37.5$ & 91 & 0.97 & $(0.73-1.29)$ & 31 & 1.43 & $(0.84-2.43)$ & 71 & 1.14 & $(0.84-1.55)$ & 24 & 1.27 & $(0.69-2.34)$ & 162 & 1.02 & $(0.82-1.27)$ & 55 & 1.39 & $(0.93-2.08)$ \\
\hline
\end{tabular}

The APCs (\% per year) of incidence rates of lung cancer for the period 1995-2009 are shown in Table S5. Among men residing in areas with the lowest residential exposure to each pollutant, significantly negative APCs emerged, whereas non significant APCs emerged among women (Table S5). Men under 75 years of age showed significantly negative APCs in areas with the lowest exposure to all pollutants and in areas with intermediate exposure to $\mathrm{C}_{6} \mathrm{H}_{6} \quad(\mathrm{APC}=-5.29 \%$; 95\%CI:-9.2;-1.2), $\mathrm{NO}_{2}$ (APC=-5.50\%; 95\%CI:-9.6;-1.2), and $\mathrm{SO}_{2}$ (APC=-4.8\% per year; 95\% CI: -7.0;-2.6). Temporal trends showed no variability in the APCs among women.

The APCs (\% per year) incidence rates of bladder cancer for the period 1995-2009 are reported in Table S6. APCs variability were not observed in both sexes and in classes of age or in overall age group.

\section{Discussion}

According to IARC, air pollution is a Group 1 carcinogen, which causes lung cancer and is associated with an increased risk of bladder cancer [10]. This population-based study assessed the risk of lung and bladder cancers among people residing in the Monfalcone area, northeastern Italy. The area is covered by a population-based cancer registry and it is characterized by the emissions, among other sources, of pollutants from a coal-fired and oil thermal power plant located near the city center.

An excess risk of lung cancer was associated with residential exposure to the highest tertile of $\mathrm{C}_{6} \mathrm{H}_{6}, \mathrm{NO}_{2}, \mathrm{PM} 10$, and $\mathrm{SO}_{2}$ only in women aged 75 years or older - an excess risk restricted to the lung cancer types other than SCC or ADK. Conversely, no excess risk was observed in men of all ages and women under 75 years of age. With regard to bladder cancer, in these women an excess risk was associated with the highest tertile of exposure to $\mathrm{C}_{6} \mathrm{H}_{6}$ and $\mathrm{NO}_{2}$ and with an intermediate tertile of exposure to $\mathrm{C}_{6} \mathrm{H}_{6}, \mathrm{NO}_{2}$, and $\mathrm{PM} 10$. 
The study findings seem to support the hypothesis that the residential exposure to high levels of air pollutants may be associated with an excess risk of incidence of lung and bladder cancers, though the reported excess risks were restricted to older women. The lack of evidence relative to intense exposure to air pollution and lung and/or bladder cancers in men might be explained by heavy smoking habits in both sexes [http://www.epicentro.iss.it/passi/] and/or by occupational activities in men (e.g., shipbuilding industries) that put them at high risk of these cancers $[15,16,17,18]$.

The analysis by histological subtypes of lung cancer shows some peculiarities. It is well-known that air pollution in urban areas is a risk factor for ADK [19], while smoking, occupational exposure, and living near pollutant sources may play a more specific role in the etiology of SCC and small cell carcinoma $[1,20]$. Excess of OLC in women aged 75 years or older living in areas with high exposure to the studied atmospheric pollutants may be due in part to smoking habits, the main cause of small cell carcinoma. It could be also explained by the reduced variability between the lowest and the highest tertile of exposure to all pollutants. Moreover, the association with exposure to $\mathrm{C}_{6} \mathrm{H}_{6}$ or $^{\mathrm{NO}_{2}}$ suggests that the excess risk of lung and bladder cancers, if attributable to air pollution, is due in particular to traffic, as it is the main source of emission of $\mathrm{C}_{6} \mathrm{H}_{6}$ and $\mathrm{NO}_{2}$ [21] while thermal power plant, home heating and diesel-engines are the main sources of emission of $\mathrm{SO}_{2}$ [6]. Recent research has shown a possible association between exposure to high level of nitrogen dioxide and excess risk of lung cancer [22]. The contribution of the various sources of pollution is confirmed by the technique of apportionment, i.e., road traffic is responsible for $62 \%$ of $\mathrm{C}_{6} \mathrm{H}_{6}, 55 \%$ of $\mathrm{NO}_{2}$, and $87 \%$ of PM10.

This descriptive investigation has some limitations, common to other observational studies. A first important factor not considered in this study is the occupational exposure, and in particular, the exposure to asbestos related to shipbuilding [23], which is associated with increased risks of mesotheliomas and ADK [24,25]. Occupational exposure could affect results differently between males and females.

Secondly, information on smoking, an important confounder, was lacking in this investigation. This variable was, thus, not included in the analysis, because the regional healthcare population database does not report information on this habit. We defined subgroups by sex and age group with different proportions of smokers to minimize smoke confounding. However, this indirect method cannot rule out a tobacco confounder residual effect in the results.

Thirdly, no information was available about the daily time spent in each risk area with different levels of exposures. Finally, the presence of other industries, port, airport and high traffic road near the residential study areas may hamper interpretation of results on the role of air pollution produced by the thermal power plant alone.

An individual human biomonitoring study, with a questionnaire investigating smoking habits, lifestyles, and occupational exposures, is currently underway on the population of the study area. This will allow an evaluation of the actual prevalence of smoking habits in both sexes and classes of age. It is also worth stressing that for lung and bladder cancer cases diagnosed from 1995 to 2009, the relevant period of residential exposure dates at least 30 years before diagnosis (in this case, residential exposures that have occurred between 1965 and 1994). We have therefore assumed that the exposures measured in 1998 were representative of that time period.

However, this study has some strengths. The incidence cases and the study population were derived from two validated regional databases (CR-FVG and healthcare population), which cover overall resident population of the study area. Furthermore, as environmental exposure is concerned, we assumed the residential location of the participants as a proxy of individual exposure. This assumption is based on geocoded residential address and use of mathematical models of air pollution distribution.

In conclusion, the findings of this descriptive study indicate that air pollution may have a role with regard to the risk of lung and bladder cancers, though limited to women aged $\geq 75$ years. These persons represented approximately $11 \%$ of all the cases of lung and bladder cancers in this population. Further analytical investigations are necessary to shed light on the possible 
determinants of these increased risks, in particular, air pollutants from multiple industrial sources, road, port and airport traffic, home heating, as well as on the role of occupation, smoking habits, and other lifestyles.

Supplementary Materials: The followings are available online at www.mdpi.com/link:

Table S1: Number of incident cases of lung cancer, age standardized rates (ASR) with corresponding 95\% confidence intervals (CI), by sex, tertile of exposure and, age group. 1995-2009 in 14 municipalities.

Table S2: Number of incident cases of lung carcinomas, age standardized rates (ASR) with corresponding 95\% confidence intervals (CI), by sex, morphology, tertile of exposure, and age group. 1995-2009 in 14 municipalities.

Table S3: Number of incident cases of lung carcinomas, incidence rate ratio (IRR) with corresponding 95\% confidence intervals (CI), by sex, morphology, tertile of exposure, and age group. 1995-2009 in 14 municipalities.

Table S4: Number of incident cases of bladder cancer, age standardized rates (ASR) with corresponding 95\% confidence intervals (CI), by sex, tertile of exposure, and age group. 1995-2009 in 14 municipalities.

Table S5: Annual percent changes (APC) and corresponding 95\% confidence intervals (CI), of lung cancer incidence by sex, tertile of exposure, and age group. 1995-2009 in 14 municipalities.

Table S6: Annual percent changes (APC) and corresponding 95\% confidence intervals (CI), of bladder cancer incidence by sex, tertile of exposure, and age group. 1995-2009 in 14 municipalities.

Acknowledgments: The authors wish to thank Mrs T. Angelin for recoding and validating morphology codes of lung and bladder cancers and Mrs L. Mei for editorial support.

Author Contributions: Paolo Collarile, Ettore Bidoli, Fabio Barbone, and Diego Serraino wrote the primary manuscript; Paolo Collarile, and Ettore Bidoli performed all analyses; Paolo Collarile, Ettore Bidoli, Stefania Del Zotto, Chiara Panato, and Diego Serraino participated in the acquisition of incidence data; Paolo Collarile, Ettore Bidoli, and Stefania Del Zotto participated in the acquisition of population data; Paolo Collarile, and Loris Zanier geocoded the population; Simonetta Fuser, Fulvio Stel, and Ilaria Gallai calculated the deposition model of thermal power plant emissions; Diego Serraino, Fabio Barbone, and Loris Zanier promoted this study as members of the Regional Observatory of "Health and Environment"; All authors read, participated in discussions of appropriate groups for analysis and interpretation of results, and they all approved the final manuscript.

Conflicts of Interest: The Authors declare that they have no conflict of interest.

\section{References}

1. López-Cima MF, García-Pérez J, Pérez-Gómez B, Aragonés N, López-Abente G, Tardón A, Pollán M. Lung cancer risk and pollution in an industrial region of Northern Spain: a hospital-based case-control study. Int J Health Geogr 2011, Jan 25;10:10. doi: 10.1186/1476-072X-10-10.

2. Field RW. Withers BL. Occupational and environmental causes of lung cancer. Clinics Chest Med 2012, 33, 681-703. doi: 10.1016/j.ccm.2012.07.001.

3. Sava F, Carlsten C. Respiratory health effects of ambient air pollution: an update. Clinics Chest Med 2012, 33, 759-769.

4. International Agency for Research on Cancer. Monographs on the evaluation of the carcinogenic risk of chemicals to humans. Vol. 105: Diesel and Gasoline Engine Exhausts and some Nitroarenes. IARC: Lyon, 2013.

5. Barbone F, Bovenzi M, Cavallieri F, Stanta G. Air pollution and lung cancer in Trieste. Italy. Am J Epidemiol 1995, 141, 1161-1169.

6. Nyberg F, Gustavsson P, Jarup L, Bellander T, Berglind N, Jakobsson R, Pershagen G. Urban air pollution and lung cancer in Stockholm. Epidemiology 2000, 11, 487-495. 
7. International Agency for Research on Cancer. Monographs on the evaluation of the carcinogenic risk of chemicals to humans. Vol. 99: Some Aromatic Amines, Organic Dyes, and Related Exposures. IARC: Lyon, 2010.

8. Barbone F, Franceschi S, Talamini R, Bidoli E, La Vecchia C. Occupational and bladder cancer in Pordenone (North-east Italy): a case control study. Int J Epidemiol 1994, 23, 58-65.

9. Malats N, Real FX. Epidemiology of bladder cancer. Hematol Oncol Clin North Am 2015, 29, 177-189.

10. International Agency for Research on Cancer. Monographs on the evaluation of the carcinogenic risk of chemicals to humans. Vol. 109: Outdoor Air Pollution. IARC: Lyon, 2016.

11. Bidoli E, Barbone F, Collarile P, Valent F, Zanier L, Daris F, Gini A, Birri S, Serraino D. Residence $n$ proximity o fan iron foundry and risk of lung cancer in the municipality of Trieste, Italy, 1995-2009. Int J Environ Res Public Health 2015, 12, 9025-9035.

12. Rothman KJ, Greenland S, Lash TL. Modern Epidemiology. 3rd Edition. Lippincott. Williams \& Wilkins: Philadelphia, PA, 2008.

13. Kim HJ, Fay MP, Feuer EJ, Midthune DN. Permutation tests for joinpoint regression with applications to cancer rates. Stat Med 2000, 19, 335-351. Erratum in: 2001, 20, 655.

14. National Cancer Institute: Joinpoint Regression Program. Volume version 4.0.4. 2013. Released May 6, 2013: https://surveillance.cancer.gov/joinpoint/revisions.html (last access on June 2013).

15. International Agency for Research on Cancer. Monographs on the evaluation of the carcinogenic risk of chemicals to humans. Vol. 92: Some Non-heterocyclic Polycyclic Aromatic Hydrocarbons and Some Related Exposures. IARC: Lyon, 2010.

16. International Agency for Research on Cancer. Monographs on the evaluation of the carcinogenic risk of chemicals to humans. Vol. 98: Painting, Firefighting, and Shiftwork. IARC: Lyon, 2010.

17. International Agency for Research on Cancer. Monographs on the evaluation of the carcinogenic risk of chemicals to humans. Vol. 99: Some Aromatic Amines, Organic Dyes, and Related Exposures. IARC: Lyon, 2010.

18. International Agency for Research on Cancer. Monographs on the evaluation of the carcinogenic risk of chemicals to humans. Vol. 100F: Chemical Agents and Related Occupations. IARC: Lyon. 2012

19. Raaschou-Nielsen O, Andersen ZJ, Beelen R, Samoli E, Stafoggia M, Weinmayr G, Hoffmann B, Fischer P, Nieuwenhuijsen MJ, Brunekreef B, Xun WW, Katsouyanni K, Dimakopoulou K, Sommar J, Forsberg B, Modig L, Oudin A, Oftedal B, Schwarze PE, Nafstad P, De Faire U, Pedersen NL, Ostenson CG, Fratiglioni L, Penell J, Korek M, Pershagen G, Eriksen KT, Sørensen M, Tjønneland A, Ellermann T, Eeftens M, Peeters PH, Meliefste K, Wang M, Bueno-de-Mesquita B, Key TJ, de Hoogh K, Concin H, Nagel G, Vilier A, Grioni S, Krogh V, Tsai MY, Ricceri F, Sacerdote C, Galassi C, Migliore E, Ranzi A, Cesaroni G, Badaloni C, Forastiere F, Tamayo I, Amiano P, Dorronsoro M, Trichopoulou A, Bamia C, Vineis $\mathrm{P}$, Hoek G. Air pollution and lung cancer incidence in 17 European cohorts: prospective analyses from the European Study of Cohorts for Air Pollution Effects (ESCAPE). Lancet Oncol 2013, 14, 813-822.

20. Lubin JH, Blot WJ. Assessment of lung cancer risk factors by histologic category. J Natl Cancer Inst 1984, 73, 383-389.

21. Caselli M, de Gennaro G, Marzocca A, Trizio L, Tutino M. Assessment of the impact of the vehicular traffic on BTEX concentration in ring roads in urban areas of Bari (Italy). Chemosphere 2010. 81. 306-311.

22. Hamra GB, Laden F, Cohen AJ, Raaschou-Nielsen O, Brauer M, Loomis D. Lung Cancer and Exposure to Nitrogen Dioxide and Traffic: A Systematic Review and Meta-Analysis. Environ Health Perspect 2015, 123, 1107-1112.

23. Bianchi C, Bianchi T. Shipbuilding and mesothelioma in Monfalcone. Italy: Indian J Occup Environ Med 2012, 16, 14-17.

24. Paris C, Benichou J, Saunier F, Metayer J, Brochard P, Thiberville L, Nouvet G. Smoking status. occupational asbestos exposure and bronchial location of lung cancer. Lung Cancer 2003, 40, 17-24.

25. Mollo F, Piolatto G, Bellis D, Andrion A, Delsedime L, Bernardi P, Pira E, Ardissone F. Asbestos exposure and histologic cell types of lung cancer in surgical and autopsy series. Int J Cancer 1990, 46, 576-80. 